\title{
Ionospheric long-term trends: can the geomagnetic control and the greenhouse hypotheses be reconciled?
}

\author{
A. V. Mikhailov \\ Institute of Terrestrial Magnetism, Ionosphere and Radio Wave Propagation, Troitsk, Moscow Region 142190, Russia \\ Received: 10 April 2006 - Revised: 12 June 2006 - Accepted: 30 June 2006 - Published: 20 October 2006
}

\begin{abstract}
The ionospheric F2-layer parameter long-term trends are considered from the geomagnetic control concept and the greenhouse hypothesis points of view. It is stressed that long-term geomagnetic activity variations are crucial for ionosphere long-term trends, as they determine the basic natural pattern of $f o \mathrm{~F} 2$ and $h m \mathrm{~F} 2$ long-term variations. The geomagnetic activity effects should be removed from the analyzed data to obtain real trends in ionospheric parameters, but this is not usually done. Only a thermosphere cooling, which is accepted as an explanation for the neutral density decrease, cannot be reconciled with negative $f o \mathrm{~F} 2$ trends revealed for the same period. A more pronounced decrease of the $\mathrm{O} / \mathrm{N}_{2}$ ratio is required which is not provided by empirical thermospheric models. Thermospheric cooling practically cannot be seen in $f o \mathrm{~F} 2$ trends, due to a weak $N m \mathrm{~F} 2$ dependence on neutral temperature; therefore, $f o \mathrm{~F} 2$ trends are mainly controlled by geomagnetic activity long-term variations. Longterm $h m \mathrm{~F} 2$ variations are also controlled by geomagnetic activity variations, as both parameters, $N m \mathrm{~F} 2$ and $h m \mathrm{~F} 2$ are related by the F2-layer formation mechanism. But $h m \mathrm{~F} 2$ is very sensitive to neutral temperature changes, so strongly damped $h m \mathrm{~F} 2$ long-term variations observed at Slough after 1972 may be considered as a direct manifestation of the thermosphere cooling. Earlier revealed negative $h m \mathrm{~F} 2$ trends in western Europe, where magnetic declination $\mathrm{D}<0$ and positive trends at the eastern stations $(\mathrm{D}>0)$, can be related to westward thermospheric wind whose role has been enhanced due to a competition between the thermosphere cooling $\left(\mathrm{CO}_{2}\right.$ increase) and its heating under increasing geomagnetic activity after the end of the 1960s.
\end{abstract}

Keywords. Ionosphere (Ionosphere-atmosphere interactions; Mid-latitude ionosphere) - Atmospheric composition and structure (Thermosphere - composition and chemistry)

Correspondence to: A. V. Mikhailov

(avm71@orc.ru)

\section{Introduction}

Long-term trends of ionospheric parameters are widely discussed during the last 15 years. Although these trends both in the F2 and E regions are very small and have no practical importance, they may serve as an indicator of long-term changes in the Earth's upper atmosphere, and their investigation may be interesting from this point of view. The interest in the problem has been greatly stimulated by the model calculations of Roble and Dickinson (1989), Rishbeth (1990), Rishbeth and Roble (1992), who predicted the ionospheric effects of the atmosphere greenhouse gas concentrations increase. Since then scientists have been trying to confirm the predicted ionospheric effects related to the thermosphere cooling (Bremer, 1992; Givishvili and Leshchenko, 1994; Ulich and Turunen, 1997; Jarvis et al., 1998; Upadhyay and Mahajan, 1998). Despite obvious contradictions with the ionospheric trend observations, the greenhouse hypothesis remains very popular. Apparently, this is due to a general interest in the anthropogenic impact on the ecological system and on the Earth's upper atmosphere. The greenhouse hypothesis has received serious support from the results of Keating et al. (2000), Emmert et al. (2004) and Marcos et al. (2005), who revealed a steady decrease in the thermospheric density over the period of 2-3 solar cycles. Not denying the very fact of the thermospheric density decrease, it should be kept in mind that the mechanism of this decrease may not be totally related to the thermosphere cooling.

An alternative approach to explain the long-term ionospheric trends has been proposed and developed by Danilov and Mikhailov (1999, 2001); Mikhailov and Marin (2000, 2001), Mikhailov (2002), Mikhailov and de la Morena (2003). This is the so-called geomagnetic control concept, which explains the main morphological features of the ionospheric trends in the F2 and $\mathrm{E}$ regions by natural variations of solar and geomagnetic activity in the framework of contemporary ionospheric storm mechanisms. At the same time, it is stressed that some additional processes are included in this scheme and their contribution becomes noticeable over

Published by Copernicus GmbH on behalf of the European Geosciences Union. 


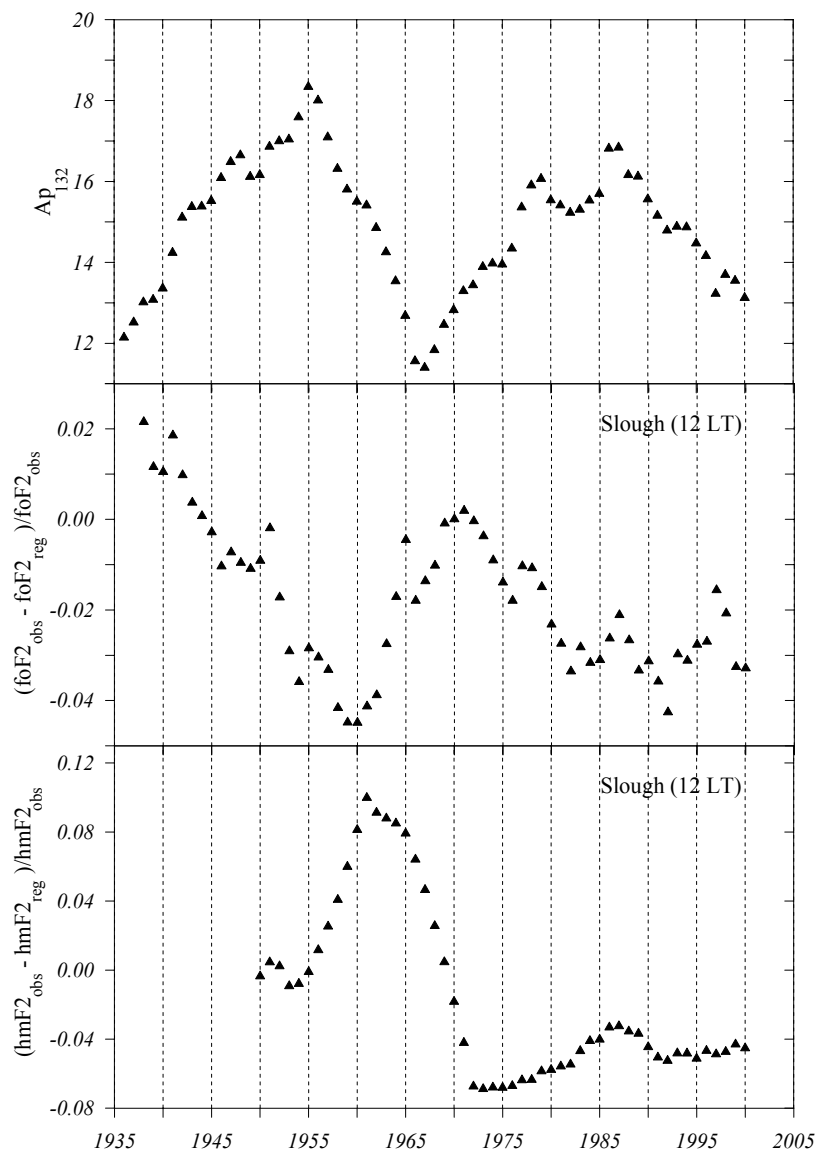

Fig. 1. 11-year running mean $A_{p}$ index, $A_{p 132}$ (top panel), $\delta f o \mathrm{~F} 2132$ (middle panel), and $\delta h m \mathrm{~F} 2132$ (bottom panel) long-term variations at noon for Slough station.

the last three decades. The thermosphere cooling due to a $\mathrm{CO}_{2}$ increase is one of these processes.

The aim of the paper is to analyze both hypotheses by taking into account the available results on the ionosphere and thermosphere parameter long-term variations, and to see if these hypotheses can be reconciled and to what extent they can be reconciled.

\section{Trend morphology}

In the framework of the geomagnetic control concept the ionospheric trends revealed in $f o \mathrm{~F} 2, h m \mathrm{~F} 2$ and $f o \mathrm{E}$ depend on geomagnetic activity. Without special efforts to remove these geomagnetic activity effects the ionospheric trends exhibit the following morphology (see earlier cited references).

1. The sign (positive/negative) of the trend depends on the phase (increasing/decreasing) of the geomagnetic activity long-term variation, as presented by the $A_{p} 132$ index (11year running mean $A_{p}$ ). Figure 1 shows the aspect of geomagnetic activity variation on $\delta f o \mathrm{~F} 2$ and $\delta h m \mathrm{~F} 2$ for the Slough station, with the longest available period of observa- tions. These dependencies until 1995 were given earlier by Mikhailov (2002) and here they are extended until 2000, using recent observations. The 11-year running mean $\delta f o \mathrm{~F} 2$ and $\delta h m \mathrm{~F} 2$ at 12:00 LT are given in comparison with the $A_{p 132}$ index variation. Periods of increasing geomagnetic activity (before 1955 and 1968-1986) are seen to correspond to negative trends in $f o \mathrm{~F} 2$ and positive trends in $h m \mathrm{~F} 2$, with a 4-5 year lag with respect to the $A_{p 132}$ variation. The inverse situation takes place for the period of decreasing geomagnetic activity (1956-1967), with strong positive foF2 and negative $h m \mathrm{~F} 2$ trends. The anti-phase variations with a 5-year shift between $A_{p 132}$ and $\delta f o \mathrm{~F} 2_{132}$ are seen even in detail, for instance, in the 1980-1990 period.

But this relationship with geomagnetic activity changes for $\delta h m F 2_{132}$ after 1972 . The $1980-1990$ peak in $A_{p 132}$ is a little bit lower than the 1955 one, and $\delta f o \mathrm{~F} 2{ }_{132}$ properly reflects this two-hump variation in $A_{p 132}$. Qualitatively, $\delta h m \mathrm{~F} 2{ }_{132}$ variations also reflect the $A_{p 132}$ changes but the magnitude of the $\delta h m \mathrm{~F} 2{ }_{132}$ peak is incomparable with the 1960-1965 one (Fig. 1, bottom). This is a very interesting result which may be related to the thermosphere cooling (to be discussed later).

The difference in the sign of the trends during increasing/decreasing phases of the geomagnetic activity takes place for all local time moments (Mikhailov and Marin, 2000). Therefore, one should be careful with the selection of time periods for trend analysis and not combine years belonging to different (rising/falling) phases of geomagnetic activity. Unfortunately, this is not taken into account in other publications devoted to the F2-layer parameter trends and this (as one of the reasons) results in chaos of various signs and magnitudes of the trends at various stations (e.g. Bremer, 1998, 2001; Upadhyay and Mahajan, 1998).

2. The $f o \mathrm{~F} 2$ trend magnitude depends on the geomagnetic (invariant) latitude, while no pronounced latitudinal dependence exists for the $h m \mathrm{~F} 2$ trends. The dependence of the $f o \mathrm{~F} 2$ trend magnitude on the geomagnetic latitude was revealed by Danilov and Mikhailov $(1998,1999)$ and that was the first indication that F2-layer trends might be related to geomagnetic activity. Mikhailov and Marin (2000) considered this dependence for the increasing phase of geomagnetic activity using various year selections and found a dependence of $f o \mathrm{~F} 2$ trends on invariant magnetic latitude. The analysis was repeated by Mikhailov (2002), using the exact years corresponding to the periods of increasing (1970-1985) and decreasing (1959-1970) geomagnetic activity. Negative foF 2 trends were confirmed for all 29 stations considered for the rising phase of geomagnetic activity and 8 available stations gave positive trends for the falling geomagnetic activity. Moreover, all trends were significant at the 95-99\% confidence level with only one exception of Ekaterinburg. The calculated $f o \mathrm{~F} 2$ trends exhibit a pronounced dependence on geomagnetic (invariant) latitude. High-latitude stations demonstrate the largest negative (positive) trends for rising (falling) periods of geomagnetic activity while low-latitude 
stations exhibit relatively small trends (Fig. 3 in Mikhailov, 2002).

Longitudinal differences in the $f o \mathrm{~F} 2$ and $h m \mathrm{~F} 2$ trends were revealed by Bremer (1998) and in $h m F 2$ trends by Marin et al. (2001). The trends were mostly negative in western Europe and positive in the region east of $30-37^{\circ} \mathrm{E}$.

3. There exist strong diurnal variations of the $f o \mathrm{~F} 2$ and $h m \mathrm{~F} 2$ trend magnitude, depending on latitude. A detailed analysis of these variations for the period with rising geomagnetic activity may be found in Mikhailov (2002) for the auroral station Sodankyla $\left(\Phi_{i n v}=63.59^{\circ}\right)$, mid-latitude station Moscow $\left(\Phi_{i n v}=51.06^{\circ}\right)$, and lower-latitude station Alma-Ata $\left(\Phi_{i n v}=35.74^{\circ}\right)$. It was shown that the $f o \mathrm{~F} 2$ trends are strongly negative at high and middle latitudes, with a tendency to be small or positive at lower latitudes. The $f o \mathrm{~F} 2$ trends revealed are significant at the $95-99 \%$ confidence level for most of the LT moments. Trends in $h m F 2$ also exhibit large diurnal variations which are consistent with the $f_{o} \mathrm{~F} 2$ trend pattern in the framework of F2-layer storm mechanism. This is an essential aspect of the F2-layer trend analyses which is never discussed in other publications. The electron concentration $N m \mathrm{~F} 2$ and the height of the F2-layer maximum $h m \mathrm{~F} 2$ are related by the mechanism of the F2-layer formation; therefore the two trends should demonstrate a consistent pattern which could be explained in the framework of the contemporary F2-layer theory.

4. A geomagnetic control of the long-term trends has been revealed in the E-region, as well (Mikhailov and de la Morena, 2003). By analogy with the F2-layer periods of increasing geomagnetic activity correspond to negative $f o \mathrm{E}$ trends while these trends are positive for the decreasing phase of geomagnetic activity. But this "natural" relationship breaks down around 1970 (on some stations later) when pronounced, positive $f o \mathrm{E}$ trends have appeared at most of the stations considered. But since this positive $f o \mathrm{E}$ trend is usually related to the worldwide greenhouse effect, in fact, it does not take place at all stations - the sign of the trends may be different. It is better to point out the spotty global pattern with unsystematic $f o$ E behavior at different stations after 1970. It is only possible to conclude that since the beginning of 1970s there has appeared an additional factor in the lower thermosphere which has broken down the normal $f o \mathrm{E}$ dependence on geomagnetic activity over a long-term time scale.

The whole enumerated trend morphology cannot be explained neither quantitatively nor qualitatively by the greenhouse hypothesis. We are still very far from the $\mathrm{CO}_{2}$ doubling in the Earth's atmosphere, but the observed trends are already 3-5 times larger than expected from the greenhouse hypothesis (Bremer, 2001). Given this, some authors stress that the changes in the upper atmosphere or the accuracy of the trends found are not sufficient enough to confirm the greenhouse hypothesis (Upadhyay and Mahajan, 1998; Ulich et al., 2000). On the other hand, the results by Keating et al. (2000), Emmert et al. (2004) and Marcos et al. (2005) on the thermospheric density decrease seem to be the only direct confirmation for this hypothesis.

\section{Numerical estimates}

A comparison of the $f o \mathrm{~F} 2$ trends obtained by different scientists has been undertaken by Laštovička et al. (2006). Daytime (11:00-14:00 LT) monthly median $f o \mathrm{~F} 2$ observations at Juliusruh for the 1976-1996 period were used in that comparison. The scatter in trends obtained turned out to be large but it was summed up that the trend was negative with a magnitude of $0.01-0.02 \mathrm{MHz} / \mathrm{year}$. An analysis by Emmert et al. (2004) fulfilled over the 1969-2001 period gave a thermospheric density $\rho$ decrease of about $-3.0 \pm 0.4 \%$ per decade at the 480-530-km range, while Marcos et al. (2005), for the same 1970-2000 period and around the $\approx 400-\mathrm{km}$ height, estimated a decrease $=-1.7 \pm 0.2 \%$ per decade, i.e. about two times less. The difference in the height range is not very important as the thermospheric neutral density above 350 $400 \mathrm{~km}$ is practically presented by atomic oxygen [O], especially during low solar activity considered in our estimates.

Let us take for our analysis a 30-year (1965-1995) period which overlaps or in general coincides with the two mentioned periods. So we may accept that over this period the foF 2 decrease is $0.3-0.6 \mathrm{MHz}$ and the thermospheric density decrease is $5-10 \%$. Furthermore, both $f_{o} \mathrm{~F} 2$ and $N m \mathrm{~F} 2(f o \mathrm{~F} 2$ $\propto N m \mathrm{~F}^{0.5}$ ) parameters will be used in our analysis. Accepting an average daytime $f o \mathrm{~F} 2=8 \mathrm{MHz}$, we have a (4-7)\% relative decrease in $f o \mathrm{~F} 2$ or $(8-14) \%$ in $N m \mathrm{~F} 2$. A $5-10 \%$ decrease in $\rho$ may be totally attributed to a corresponding decrease in $[\mathrm{O}]$ at the heights considered.

But just a thermosphere temperature Tn decrease (for instance, due to $\mathrm{CO}_{2}$ forcing) which could provide a necessary decrease in $\rho$, does not produce the required $N m \mathrm{~F} 2$ variations as the $[\mathrm{O}]$ decrease in this case is practically compensated by the $\left[\mathrm{N}_{2}\right]$ decrease while the direct effect of $\mathrm{Tn}$ variations is small (Ivanov-Kholodny and Mikhailov, 1986). This is seen from the expression for the mid-latitude daytime F2layer (Mikhailov et al., 1995)

$\Delta \lg \mathrm{Nm}=4 / 3 \Delta \lg [\mathrm{O}]-2 / 3 \Delta \lg \left[\mathrm{N}_{2}\right]-5 / 6 \Delta \lg \operatorname{Tn}$.

This expression is invariant relative to height changes in the isothermal thermosphere, so any height in the F2-region may be chosen as the basic level for estimates.

The same conclusion follows from the isobaric F2-layer concept by Rishbeth and Edwards (1989, 1990). According to this concept the F2-layer peak follows, in its variations, the level of constant atmospheric pressure. This is a good approximation, at least during daytime hours, when vertical plasma drifts are not strong. It can be shown (Mikhailov and Marin, 2000) that the $[\mathrm{O}] /\left[\mathrm{N}_{2}\right]$ ratio remains constant at any fixed value of pressure and at any temperature height profile, provided temperature and concentrations $[\mathrm{O}]$ and $\left[\mathrm{N}_{2}\right]$ are constant at the base level. Therefore, the observed negative 
trend in $N m \mathrm{~F} 2$ cannot be explained just by the thermosphere cooling and the $[\mathrm{O}] /\left[\mathrm{N}_{2}\right]$ ratio should be changed by some other way.

Dynamical processes related to neutral gas upwelling and downwelling are known to result in $[\mathrm{O}] /\left[\mathrm{N}_{2}\right]$ ratio changes, and the contemporary F2-layer storm mechanism is based on this idea (e.g. Rishbeth and Müller-Wodarg, 1999). The increasing geomagnetic activity is accompanied by an $[\mathrm{O}] /\left[\mathrm{N}_{2}\right]$ ratio decrease at high and middle latitudes, due to gas upwelling in the auroral zone, followed by its transfer to middle latitudes. This effect is reflected to some extent in modern empirical thermospheric models, such as NRLMSISE-00 (Picone et al., 2002), but its magnitude is not large enough (to be discussed later).

So the problem may be formulated as follows. Is it possible to reconcile an expected 10-20 K decrease in the thermospheric temperature under the greenhouse hypothesis (Rishbeth and Roble, 1992; Akmaev, 2003), a 5-10\% decrease in the thermospheric density (Emmert et al., 2004; Marcos et al., 2005, a (8-14)\% decrease in $N m \mathrm{~F} 2$ (Laštovička et al., 2006), and $h m \mathrm{~F} 2$ long-term variations with a small positive trend after 1972 (Fig. 1, bottom)?

At first let us check what can be obtained with the NRLMSISE-00 empirical model. Annual mean values of $\mathrm{F}_{10.7}$ are close for the two years chosen (76.3 for 1965 and 77.2 for 1995), therefore no special reduction in solar activity is needed, while the 11-year running mean $A_{p}$ values are different,12.3 and 14.4, for the two years in question (Fig. 1). All calculations were made for middle latitudes $45-55^{\circ} \mathrm{N}$, $15^{\circ} \mathrm{E}$ (close to Juliusruh location) at the $400-\mathrm{km}$ height.

According to Keeling et al. (1995), one may expect a $\leq 15 \%$ increase in $\left[\mathrm{CO}_{2}\right]$ over a 30 -year period and the thermospheric temperature decrease by $10-20 \mathrm{~K}$ at best (Rishbeth and Roble, 1992; Akmaev, 2003). So for our estimates we may accept $\Delta T n=-15 \mathrm{~K}$, and this is $\leq 2 \%$ for the annual mean $\mathrm{Tn}$ over the period considered. Due to an $A_{p}$ index increase, the annual mean temperature increases by $5-7 \mathrm{~K}$ (depending on latitude) and under expected $\Delta T n=-15 \mathrm{~K}$ we obtain an overall $T n$ decrease by $\approx 8-10 \mathrm{~K}$. This gives a $5 \%$ decrease in $\mathrm{N}_{2}$ and $\mathrm{O}_{2}$ concentrations and a $4 \%$ decrease in $[\mathrm{O}]$. Equation (1), in accordance with earlier comments, gives $\Delta N m \mathrm{~F} 2 \approx 0$ in this case. It seems that the dynamical effects on $\mathrm{O} / \mathrm{N}_{2}$ changes due to geomagnetic activity variations should be presented more strongly. Therefore, if we come from a $10 \%$ decrease in $\rho$ (Emmert et al., 2004), a 15-K decrease in $T n$, and a $10 \%$ decrease in $N m \mathrm{~F} 2$, then from Eq. (1) the required decrease in $\left[\mathrm{N}_{2}\right]$ should be $-2.5 \%$ while the NRLMSISE- 00 model gives $\Delta\left[\mathrm{N}_{2}\right]=-7 \%$ and $\Delta[\mathrm{O}]=-5 \%$, i.e. the thermosphere should be more impoverished with atomic oxygen and more abundant with molecule species under such an increase in geomagnetic activity. In case of a $5 \%$ decrease in $\rho$ (Marcos et al., 2005) the model provides the required decrease in $[\mathrm{O}]$ while the $\left[\mathrm{N}_{2}\right]$ decrease again is overestimated by $\approx 2.5 \%$.
The routinely obtained F2-layer maximum height $h m \mathrm{~F} 2$, which is usually used in trend analyses, is a much less reliable (compared to $f_{o} \mathrm{~F} 2$ ) parameter, as it is not scaled directly from ionograms but is calculated from the $\mathrm{M}(3000) \mathrm{F} 2$ parameter using empirical expressions. Nevertheless, the $h m \mathrm{~F} 2$ long-term variations are consistent with the $A_{p} 132$ and $f o \mathrm{~F} 2$ variations pattern (Fig. 1), which is explained in the framework of the geomagnetic control concept (Mikhailov, 2002). But since 1972 the situation has changed. Although qualitatively the $\delta h m \mathrm{~F} 2$ variation reflects, as it did earlier, the variations in $A_{p 132}$, its magnitude is much less compared to the 1955-1965 period (Fig. 1). This may be considered as a direct confirmation of the thermosphere cooling due to the $\mathrm{CO}_{2}$ increase - the effect which scientists are persistently looking for in the ionospheric trends. Unlike $N m \mathrm{~F} 2$, which is relatively insensitive to neutral temperature changes, $h m \mathrm{~F} 2$ is directly related to $T n$, as it is seen from the expression (Ivanov-Kholodny and Mikhailov, 1986)

$h_{m} \propto \frac{2.3 H}{3}\left\{\lg [\mathrm{O}]_{1}+\lg \beta_{1}+\lg \left(\frac{\mathrm{H}^{2}}{0.54 \mathrm{~d}}\right)\right\}+\mathrm{c} W$,

where $\mathrm{H}=\mathrm{kT}_{n} / \mathrm{mg}$ is the scale height and [O] is the concentration of atomic oxygen, $\beta$ is the linear loss coefficient at a fixed height $h_{1}, W$ (in $\mathrm{m} / \mathrm{s}$ ) is the vertical plasma drift velocity, $\mathrm{c}$ is a coefficient close to unity, $\mathrm{d}=1.38 * 10^{19} *\left(\mathrm{~T}_{n} / 1000\right)^{0.5}$ is a coefficient in the expression for the ambipolar diffusion coefficient $\mathrm{D}=\mathrm{d} /[\mathrm{O}]$.

According to the earlier estimates, neutral temperature $T n$, atomic oxygen concentration [O], and linear loss coefficient $\beta \propto\left[N_{2}\right] T_{n}^{2}$ are decreasing for the period in question. This should result in a negative $h m \mathrm{~F} 2$ trend, however, it is slightly positive for the period after 1972. The only possible explanation is to accept an increase in the vertical plasma drift $\mathrm{W}$ due to the thermospheric neutral winds enhancement. This does not look unreasonable, as the enhancement of the equatorward (or damping the poleward) thermospheric wind due to increasing geomagnetic activity is well established (e.g. Fejer et al., 2000; Emmert et al., 2001).

\section{Discussion}

It seems that the geomagnetic activity impact on the upper atmosphere has not yet been fully understood and properly taken into account in the empirical thermospheric models. A large $4 \pm 1$ year delay between long-term geomagnetic activity variations and long-term F2-layer parameter trends shown earlier on 29 stations (Mikhailov, 2002) and also clearly seen at Slough (Fig. 1) tells us that the whole Earth's atmosphere is involved with the processes provoked by geomagnetic activity. Changes in the global atmospheric circulation and related variations in the thermospheric neutral composition and temperature is the most probable mechanism. Shortterm (3-h, daily, monthly and perhaps even annual) variations of geomagnetic activity presented by corresponding indices 
only produce an effect of "ripples on the water surface" while the atmosphere lives its own life. Therefore, all attempts to remove the geomagnetic activity effects from long-term ionospheric trends, using monthly or even annual mean $A_{p}$ indices, turn out to be inefficient and only insert additional noise to the analyzed data. As it was shown in our approach (Mikhailov et al., 2002), by working with an 11-year running mean and additionally smoothed $A_{p}, \delta f o \mathrm{~F} 2$, and $\delta h m \mathrm{~F} 2$ values, it is possible to remove geomagnetic activity effects to a great extent. The residual trends after such a removal of geomagnetic activity are very small and usually statistically insignificant. This was confirmed by the results of different methods comparison using Juliusruh observations (Laštovička et al., 2006). Our $f o \mathrm{~F} 2$ residual trend turned out to be much less $(-0.00086 \mathrm{MHz} /$ year $)$ compared to other estimates (-0.01-0.02) MHz/year. But if we did not remove the geomagnetic activity effects from our results, then the trend estimated over the whole 1976-1996 period would be $\leq-$ $0.01 \mathrm{MHz} /$ year (depending on the accepted average $f o \mathrm{~F} 2=8$ $10 \mathrm{MHz}$ ), which coincides with the other estimates. It should be noted that the 1976-1996 period comprises both the rising until 1987 and the falling phases of geomagnetic activity with different trend magnitudes. For instance, if one takes only the 1976-1987 period (rising phase), the trend will be $\approx-0.03 \mathrm{MHz} / \mathrm{year}$, i.e. even higher than other estimates. Thus, large $(-0.01-0.02) \mathrm{MHz} /$ year trends obtained by other scientists are just due to geomagnetic activity effects which have not been removed properly from the analyzed data. A small negative residual trend obtained with our approach (Mikhailov et al., 2002) reflects a very long-term increase in the geomagnetic activity which took place in the 20th century.

Coming back to the main question of the paper: if the geomagnetic control and the greenhouse hypotheses can be reconciled, it should be answered - yes. The basic (natural, background) $N m \mathrm{~F} 2$ and $h m \mathrm{~F} 2$ long-term variations are controlled by long-term variations of the geomagnetic activity using standard F2-layer storm mechanisms. The thermosphere cooling due to the greenhouse effect (other possible effects of $\mathrm{CO}_{2}$ increase are not discussed in relation with the ionospheric trends) is practically not noticeable in the $f o \mathrm{~F} 2$ trends. This is due to a weak $N m \mathrm{~F} 2$ dependence on neutral temperature. Therefore, $f o \mathrm{~F} 2$ trends are completely controlled by long-term variations of the geomagnetic activity, if, of course, its effects are not removed. A two-hump structure in $A_{p} 132$ variations is clearly reproduced in the $f o \mathrm{~F} 2$ long-term variations with a 4-5 year lag (Fig. 1). This relationship is seen even in detail, for instance, in the two peaks and the valley in 1980-1990 as part of the $f o \mathrm{~F} 2$ variations. A similar relationship of long-term trends with the geomagnetic activity takes place in the ionospheric E-region, as well (Mikhilov and de la Morena, 2003), although the mechanism of this relation in the E-region is quite different (Mikhailov, 2006).
A 4-5 year delay in F2-layer trends with respect to $A_{p 132}$ variations is a very interesting and yet unexplained effect. It was revealed in our earlier trend analyses, where we proposed that such a large time delay might imply that the whole Earth's atmosphere is involved with the processes provoked by geomagnetic activity. Changes in the global atmospheric circulation and related variations in the thermospheric neutral composition and temperature is the most probable mechanism. Obviously, this time lag tells us about the characteristic time of the Earth's atmosphere. According to some model estimates, it takes about 5 years for tropospheric air to reach the mesospheric heights (Schneider et al., 2000) and this estimate seems to confirm the idea.

The situation with the $h m \mathrm{~F} 2$ trend is more complicated. There are serious problems with using routine $h m \mathrm{~F} 2$ data for trend analyses (Ulich, 2000) and the priority should be given to $f o \mathrm{~F} 2$ trends, based on direct and more reliable observations, while $h m \mathrm{~F} 2$ trends may be considered only as complimentary information which should not at least contradict the mechanism proposed. However, any hypothesis should explain both $N m \mathrm{~F} 2$ and $h m \mathrm{~F} 2$ long-term trends in a consistent way, as these parameters are related by the F2layer formation mechanism. Until now no reasonable hypothesis of the F2-layer parameter trends has been proposed, except for the geomagnetic control concept. The anti-phase $N m \mathrm{~F} 2$ and $h m \mathrm{~F} 2$ long-term variations take place at Slough (Fig. 1) and such variations are explained in the framework of the F2-layer storm mechanism (Mikhailov, 2002 and references therein). Unlike $N m \mathrm{~F} 2$, which is not very sensitive to the neutral temperature and vertical plasma drift (during daytime) variations, $h m \mathrm{~F} 2$ depends directly on both parameters (Eq. 2). Therefore, the expected thermosphere cooling under the greenhouse hypothesis should be seen in $h m \mathrm{~F} 2$ variations (see also Rishbeth, 1990). Indeed, the "humps" in $A_{p 132}$ around 1955 and 1987 are close in magnitude and this is adequately reflected in $f o \mathrm{~F} 2$ variations but not in $h m \mathrm{~F} 2$ variations (Fig. 1). This result may be considered as a direct confirmation for the thermosphere cooling. Although we still have $h m \mathrm{~F} 2$ variations which follow the geomagnetic activity ones, the amplitude of these changes is strongly depressed.

According to earlier quantitative estimates the only possibility to maintain a positive $h m \mathrm{~F} 2$ trend after 1972 is to accept an increase in the vertical plasma drift $W$ due to thermospheric winds. Obviously, a similar $W$ increase took place during the previous period of elevated geomagnetic activity around 1955, but then it was in line with the increase in thermosphere temperature and linear loss coefficient, in accordance with the F2-layer storm mechanism and this gave a large peak in $h m \mathrm{~F} 2$ variations (Fig. 1). After 1972 we have small negative trends in all aeronomic parameters (see Eq. (2)), as a result of competition between the thermosphere cooling (due to a $\mathrm{CO}_{2}$ increase) and heating (due to an $A_{p 132}$ increase). Under such conditions, the contribution of $W$ to $h m \mathrm{~F} 2$ variations increases, that is the disturbed thermospheric winds start to play the leading role. 


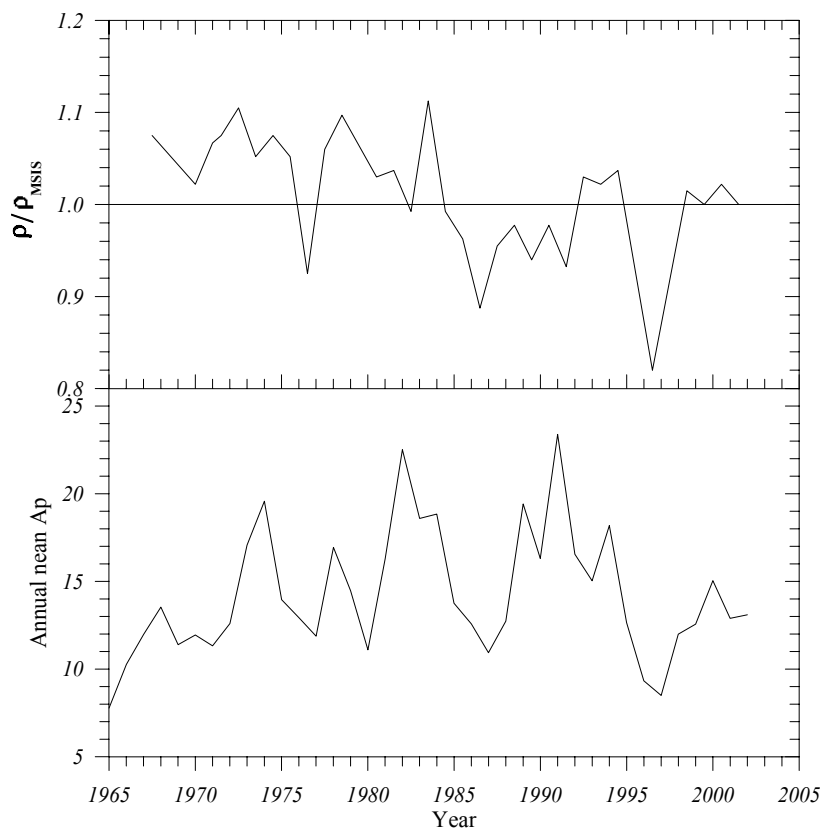

Fig. 2. Annual averages $\rho / \rho_{M S I S}$ (from Emmert et al., 2004) and annual mean $A_{p}$ indices.

The confirmation to these ideas can be found in previous results of the ionospheric trend analyses. Bremer (1998) has revealed negative trends in $h m \mathrm{~F} 2$ in the European region west of $30^{\circ} \mathrm{E}$ while positive trends dominated in the region to the east from $30^{\circ} \mathrm{E}$. A similar conclusion on $h m \mathrm{~F} 2$ trends has been obtained by Marin et al. (2001), who used quite a different method for trend analysis. Whereas most of the analyzed stations located in the $0-22^{\circ} \mathrm{E}$ longitudinal sector exhibited negative trends, those eastward from $37^{\circ} \mathrm{E}$ presented significant positive trends. Stations located in the transitional (26$\left.33^{\circ} \mathrm{E}\right)$ region gave small and insignificant positive or negative trends. The analyzed period includes the rising phase of geomagnetic activity after 1965 when the thermosphere cooling effects have become noticeable. This longitudinal separation clearly indicates the geomagnetic field of origin of the effect. The $20^{\circ} \mathrm{E}$ longitude in Europe corresponds to a zero declination (D) of the magnetic field, therefore, zonal (westward) wind Vny will produce negative plasma drift in western Europe, where $\mathrm{D}<0$, and positive drift in the eastern region, where $\mathrm{D}>0$, in accordance with the expression $\mathrm{W}=-$ VnySinICosISinD, where I is magnetic inclination positive in the Northern Hemisphere. An enhancement of the disturbance westward thermospheric wind has been reported by Emmert et al. (2001) using WINDII observations. Both zonal and meridional perturbations were found to increase roughly linearly with $K_{p}$ and expand to lower latitudes with increasing magnetic activity.

Summarizing this part of our analysis it should be stressed that the mechanism of the F2-layer parameter long-term trends is pretty sophisticated and cannot be reduced to one process (the thermosphere cooling, for instance), but in accordance with the theory of F2-layer formation it includes some different processes, the role and contribution each of them vary with conditions. Without the thermosphere cooling due to a $\mathrm{CO}_{2}$ increase the $N m \mathrm{~F} 2$ and $h m \mathrm{~F} 2$ trend pattern would be determined by long-term variations of geomagnetic activity via the standard F2-layer storm mechanisms. This still takes place for $N m \mathrm{~F} 2$ but not for $h m \mathrm{~F} 2$ trends, for which the situation has changed after 1972 when the thermosphere cooling became noticeable and the disturbed (again due to the increasing geomagnetic activity) winds appeared on the stage to play an important role.

In the framework of our analysis we should say some words about the results by Keating et al. (2000), Emmert et al. (2004) and Marcos et al. (2005), as they are closely related to the ionospheric trends mechanism. In the cited papers it is directly stated that the observed density decrease is associated with the cooling effect of increased greenhouse gas concentrations. Yes, a $20 \mathrm{~K}$ decrease in $T n$ provides the observed $\approx 10 \%$ decrease in neutral density (Emmert et al., 2004 ) at $400 \mathrm{~km}$ over a 30 -year period. A $10-\mathrm{K}$ decrease in $T n$ is needed for a 5\% decrease in $\rho$ in the case of the Marcos et al. (2005) results. But as it was shown earlier just a temperature decrease alone does not explain the negative trends in $f o \mathrm{~F} 2$ obtained over about the same period; the result has been confirmed by different authors using all available ionosonde observations and should be considered as reliable. To reconcile these results we should accept for the period in question more pronounced $\mathrm{O} / \mathrm{N}_{2}$ changes (with larger [O] and less $\left[\mathrm{N}_{2}\right]$ decreases) under the variations of geomagnetic activity than provide empirical thermosphere models, NRLMSISE00 , for instance. The effect is probably related to gas upwelling in the auroral zone, due to the thermosphere heating under increasing geomagnetic activity. Therefore, the observed density decrease is due to two processes - the thermosphere cooling and the atomic oxygen abundance decrease resulting from the disturbed thermospheric circulation. But such neutral composition changes are not predicted by modern thermospheric empirical models.

The restriction of empirical models in describing disturbed conditions has been stressed repeatedly. For instance, a comparison of thermospheric parameters retrieved from EISCAT (auroral zone) observations with MSIS-86 predictions (Mikhailov and Lilensten, 2004) has shown that the model strongly overestimates both total gas density $\rho$ and atomic oxygen concentration at $300 \mathrm{~km}$ for disturbed days with an average $\rho_{\text {cal }} / \rho_{M S I S}=0.52$ and $[\mathrm{O}]_{\text {cal }} /[\mathrm{O}]_{M S I S}=0.43$. Both differences are significant at the $99 \%$ confidence level. A similar result was obtained by Litvin et al. (2000) by analyzing with the energy equation Millstone Hill (middle latitudes) incoherent scatter observations for a disturbed period of 5-11 June 1991. During the most active phase of the disturbance, they found [O] to be lower by a factor of 2 than MSIS-86 predictions. Negative F2-layer storm effects, which are due to an $\mathrm{O} / \mathrm{N}_{2}$ ratio decrease, cannot be satisfactory 
modelled without a special fitting of aeronomic parameters for each particular ionospheric storm (e.g. Richards et al., 1989, 1994; Buonsanto, 1999).

The importance of the removal of the effects of geomagnetic activity for adequate analysis of the long-term trends has been stressed in this paper, as well as in our previous publications on the problem. When this is not properly done or when geomagnetic effects are removed only partly, the analyzed long-term variations, in fact, present the variations of geomagnetic activity and it is not clear which trends are analyzed. The results by Emmert et al. (2004) are not free from this drawback, as well. Their linear trend $-3.1 \pm 0.9 \%$ per decade (their Fig. 2) was drawn over $\rho / \rho_{M S I S}$ values which demonstrate large but systematic variations. Our analysis of their results (Fig. 2) shows that practically all ups and downs in $\rho / \rho_{M S I S}$ variations coincide within 1 year with changes (corresponding ups, downs or bends in the curve) in the annual mean $A_{p}$ index. On the one hand, this tells us that NRLMSISE-00 used in their analysis does not work out properly the long-term variations in solar and geomagnetic activity. On the other hand, this means that long-term geomagnetic activity effects were not removed from the analyzed $\rho / \rho_{M S I S}$ variations. Which long-term trend in the thermospheric density will be left after such a removal is an open question.

The results by Marcos et al. (2005), obtained over the same period, give a two times smaller trend in the thermospheric density $-1.7 \pm 0.2 \%$ per decade. One of the reasons for this difference may be due to the reduction procedure used in their analysis. A relatively old thermospheric model by Jacchia (1970) has been chosen for the drag measurements reduction. Obviously, this choice was not random, as among many others this is the only model which takes into account the running annual mean $K_{p}$ index variations. This feature of the model is very important for long-term trend analysis, as it allows one to remove or suppress the geomagnetic activity long-term variation effects. From this point of view a more moderate trend obtained by Marcos et al. (2005) looks more realistic.

\section{Conclusions}

The main results of our consideration may be summarized as follows.

1. Long-term variations of geomagnetic activity are crucial for ionosphere and thermosphere long-term trend analyses. Via changes in thermospheric circulation and corresponding changes in neutral composition and temperature the geomagnetic activity determines the basic pattern of the ionospheric trends. Additional processes, such as thermosphere cooling due to a $\mathrm{CO}_{2}$ increase, overlapping the basic pattern may change it to some extent but is unable to explain the observed ionospheric trend morphology. Therefore, before any analysis of long-term trends, basic long-term varia- tions related to geomagnetic activity should be removed from the analyzed material. This needs special methods and is usually not done by researchers; therefore, the resultant trends turn out to be strongly "contaminated" with the geomagnetic activity effects.

2. Just a thermosphere temperature decrease, which is accepted by many as an explanation for the neutral density decrease, cannot explain negative $f o \mathrm{~F} 2$ trends revealed for the same period by many ionospheric research studies. The observed density decrease comprises of two parts - one is due to direct thermosphere cooling and the other to an atomic oxygen abundance decrease, presumably the result of disturbed thermospheric circulation. The quantitative contribution of each process depends on the accepted decrease in the thermospheric density. But there are doubts in the magnitude of the neutral density trend given by Emmert et al. (2004), as their results are not free from geomagnetic activity effects.

3. Thermosphere cooling can be reconciled with the geomagnetic control concept by accepting a more pronounced dependence of the $\mathrm{O} / \mathrm{N}_{2}$ ratio on geomagnetic activity than is presented by empirical thermospheric models like NRLMSISE-00. This drawback of empirical models on a short-term time scale is well-known and has been stressed repeatedly. The effects of long-term geomagnetic activity variations are not taken into account in such models, in principle, and this is seen in the Emmert et al. (2004) results.

4. Thermospheric cooling practically cannot be seen in $f_{o} \mathrm{~F} 2$ trends, due to a weak $\mathrm{Nm} \mathrm{F} 2$ dependence on neutral temperature; therefore, $f o \mathrm{~F} 2$ trends are mainly controlled by geomagnetic activity long-term variations. This is confirmed by long-term $f o \mathrm{~F} 2$ variations revealed for the whole 1938-2000 period at the Slough station. Large (-0.01-0.02) MHz/year trends obtained by a majority of researchers (Laštovička et al., 2006) just reflect the unremoved effects of geomagnetic activity for the period in question. Such trends would be positive if the 1960-1970 period was considered. Real residual $f o \mathrm{~F} 2$ trends, which are free to a great extent of geomagnetic activity effects, are very small and usually statistically insignificant.

5. Long-term $h m \mathrm{~F} 2$ variations are also controlled by geomagnetic activity variations, as both parameters $N m \mathrm{~F} 2$ and $h m \mathrm{~F} 2$ are related by the F2-layer formation mechanism. But unlike $N m \mathrm{~F} 2$ the F2-layer maximum height is very sensitive to neutral temperature and thermospheric wind variations. Strongly damped $h m \mathrm{~F} 2$ long-term variations observed at Slough after 1972 are a direct manifestation of the thermosphere cooling. A competition between thermosphere heating (due to the increasing geomagnetic activity) and its cooling (due to $\mathrm{CO}_{2}$ increase) gave an opportunity for thermospheric winds to appear themselves. Revealed earlier by Bremer (1998) and Marin et al. (2001) negative $h m F 2$ trends in Western Europe (where magnetic declination $\mathrm{D}<0$ ) and positive trends in the eastern stations (where $\mathrm{D}>0$ ) can be related to enhanced westward thermospheric wind. 
Acknowledgements. Topical Editor M. Pinnock thanks two referees for their help in evaluating this paper.

\section{References}

Akmaev, R. A.: Thermospheric resistance to "greenhouse cooling": Effect of the collisional excitation rate by atomic oxygen on the thermal response to $\mathrm{CO}_{2}$ forcing, J. Geophys. Res., 108, 1292, doi:10.1029/2003JA009896, 2003.

Bremer, J.: Ionospheric trends in mid-latitudes as a possible indicator of the atmospheric greenhouse effect, J. Atmos. Terr. Phys., 54, 1505-1511, 1992.

Bremer, J.: Trends in the ionospheric E and F regions over Europe, Ann. Geophys., 16, 986-996, 1998, http://www.ann-geophys.net/16/986/1998/.

Bremer, J.: Trends in the thermosphere derived from global ionosonde observations, Adv. Space Res., 28, (7)997-(7)1006, 2001.

Buonsanto, M. J.: Ionospheric storms - a review, Space Sci. Rev., 88, 563-601, 1999.

Danilov, A. D. and Mikhailov, A. V.: Long-term trends of the F2layer critical frequencies: a new Approach, Proceedings of the 2nd COST 251 Workshop "Algorithms and models for COST 251 Final Product", 30-31 March, 1998, Side, Turkey, Rutherford Appleton Lab., UK, 114-121, 1998.

Danilov, A. D. and Mikhailov, A. V.: Spatial and seasonal variations of the $f o \mathrm{~F} 2$ long-term trends, Ann. Geophys., 17, 1239-1243, 1999 , http://www.ann-geophys.net/17/1239/1999/.

Danilov, A. D. and Mikhailov, A. V.: F2-layer parameters longterm trends at the Argentine Islands and Port Stanley stations, Ann. Geophys., 19, 341-349, 2001,

http://www.ann-geophys.net/19/341/2001/.

Emmert, J. T., Fejer, B. G., Fesen, C. G., Shepherd, G. G., and Solheim, B. H.: Climatology of middle- and low-latitude daytime F region disturbance neutral winds measured by Wind Imaging Interferometer (WINDII), J. Geophys. Res., 106, 24 701-24 712, 2001.

Emmert, J. T., Picone, J. M., and Lean, J. L.: Global change in the thermosphere: Compelling evidence of a secular decrease in density, J. Geophys. Res., 109, A02301, doi:10.1029/2003JA0101176, 2004.

Fejer, B. G. and Emmert, J. T.: Average daytime F region disturbance neutral winds measured by UARS: Initial results, Geophys. Res. Lett., 27, 1859-1862, 2000.

Givishvili, G. V. and Leshchenko, L. N.: Possible proofs of presence of technogenic impact on the mid-latitude ionosphere (in Russian), Doklady RAN, 334, (1), 213-214, 1994.

Jacchia, L. G.: New static models of the thermosphere and exosphere with empirical temperature profiles, Spec. Rep. Smithon. Astrophys. Obs., No 313, 87, 1970.

Jarvis, M. J., Jenkins, B., and Rodgers, G. A.: Southern hemisphere observations of a long-term decrease in $\mathrm{F}$ region altitude and thermospheric wind providing possible evidence for global thermospheric cooling, J. Geophys. Res., 103, 20 774-20 787, 1998.

Ivanov-Kholodny, G. S. and Mikhailov, A. V.: The prediction of ionospheric conditions, Reidel, Dordrecht, 168, 1986.

Keating, G. M., Tolson, R. H., and Bradford, M. S.: Evidence of long term global decline in the Earth's thermospheric density ap- parently related to anthropogenic effects, Geophys. Res. Lett., 27, 1523-1526, 2000.

Keeling, C. D., Whorf, T. P., Wahlen, M., and van der Pflicht, J.: Interannual extremes in the rate of rise of atmospheric carbon dioxide since 1980, Nature, 375, 666-670, 1995.

Laštovièka, J., Mikhailov, A. V., Ulich, T., Bremer, J., Elias, A. G., Ortiz de Adler, N., Jara, V., Abarca del Rio, R., Foppiano, A. J., Ovalle, E., and Danilov, A. D.: Long-term trends in foF2: a comparison of various methods (in press), J. Atmos. Solar-Terr. Phys., 2006.

Marcos, F. A., Wise, J. O., Kendra, M. J., Grossbard, N. J., and Bowman, B. R.: Detection of long-term decrease in thermospheric neutral density, Geoph. Res. Lett., 32, L04103, doi:10.1029/2004GL021269, 2005.

Litvin, A., Oliver, W. L., Picone, J. M., and Buonsanto, M. J.: The upper atmosphere during June 5-11, 1991, J. Geophys. Res., 105, 12 789-12 796, 2000.

Marin, D., Mikhailov, A. V., de la Morena, B. A., and Herraiz, M.: Long-term $h m \mathrm{~F} 2$ trends in the Eurasian longitudinal sector on the ground-based ionosonde observations, 2001, Ann. Geophys., 19, 761-772, 2001, http://www.ann-geophys.net/19/761/2001/.

Mikhailov, A. V., Skoblin, M. G., and Förster, M.: Day-time F2layer positive storm effect at middle and lower latitudes, Ann. Geophys., 13, 532-540, 1995, http://www.ann-geophys.net/13/532/1995/.

Mikhailov, A. V.: The geomagnetic control concept of the F2-layer parameter long-term trends, Phys. Chem. Earth, 27, 595-606, 2002.

Mikhailov, A. V.: Trends in the ionospheric E-region, Phys. Chem. Earth, 31, 22-23, 2006.

Mikhailov, A. V. and Marin, D.: Geomagnetic control of the $f_{o} \mathrm{~F} 2$ long-term trends, Ann. Geophys., 18, 653-665, 2002, http://www.ann-geophys.net/18/653/2002/.

Mikhailov, A. V. and Marin, D.: An interpretation of the $f o \mathrm{~F} 2$ and $h m \mathrm{~F} 2$ long-term trends in the framework of the geomagnetic control concept, Ann. Geophys., 19, 733-748, 2001, http://www.ann-geophys.net/19/733/2001/.

Mikhailov, A. V., Marin, D., Leschinskaya, T. Yu., and Herraiz, M.: A revised approach to the $f o \mathrm{~F} 2$ long-term trends analysis, Ann. Geophys., 20, 1663-1675, 2002, http://www.ann-geophys.net/20/1663/2002/.

Mikhailov, A. V. and de la Morena, B. A.: Long-term trends of foE and geomagnetic activity variations, Ann. Geophys., 21, 751760, 2003, http://www.ann-geophys.net/21/751/2003/.

Mikhailov, A. V. and Lilensten, J.: A revised method to extract thermospheric parameters from incoherent scatter observations, Ann. Geophysics, Supp., 47, 985-1008, 2004.

Picone, J. M., Hedin, A. E., and Drob, D. P., and Aikin, A. C.: NRLMSISE-00 empirical model of the atmosphere: Statistical comparison and scientific issues, J. Geophys. Res., 107, 1468, doi:10.1029/2002JA009430, 2002.

Richards, P. G., Torr, D. G., Buonsanto, M. J., and Miller, K. L.: The behaviour of the electron density and temperature at Millstone Hill during the equinox transition study September 1984, J. Geophys. Res., 94, 16969-16975, 1989.

Richards, P. G., Torr, D. G., Buonsanto, M. J., and Sipler, D. P.: Ionospheric effects of the March 1990 magnetic storm: Compar- 
ison of theory and measurement, J. Geophys. Res., 99, 23359 $23365,1994$.

Rishbeth, H.: A greenhouse effect in the ionosphere?, Planet. Space Sci., 38, 945-948, 1990.

Rishbeth, H. and Edwards, R.: The isobaric F2 layer, J. Atmos. Terr. Phys., 51, 321-338, 1989.

Rishbeth, H. and Edwards, R.: Modeling the F2 layer peak height in terms of atmospheric pressure, Radio Sci., 25, 757-769, 1990.

Rishbeth, H. and Roble, R. G.: Cooling of the upper atmosphere by enhanced greenhouse gases - Modelling of thermospheric and ionospheric effects, Planet. Space Sci., 40, 1011-1026, 1992.

Rishbeth, H. and Müller-Wodarg, I. C. F.: Vertical circulation and thermospheric composition: a modelling study, Ann. Geophys., 17, 794-805, 1999.

Roble, R. G. and Dickinson, R. E.: How will changes in carbon dioxide and methane modify the mean structure of the mesosphere and thermosphere ?, Geophys. Res. Lett., 16, 1441-1444, 1989.
Schneider, H. R., Jones, D. B. A., Wofsy, S. C., and McElroy, M. B.: Analysis of residual mean transport in the stratosphere; 2. Distributions of $\mathrm{CO}_{2}$ and mean age, J. Geophys. Res., 105, 20013 $20024,2000$.

Ulich, T. and Turunen, E.: Evidence for long-term cooling of the upper atmosphere in ionospheric data, Geophys. Res. Lett., 24, 1103-1106, 1997.

Ulich, Th., Turunen, E., and Karinen, A.: Global change and changing upper atmosphere-Observations, in: Solar variability and long-term trends in the ionosphere, Sodankyla Geophysical observatory publications, No. 87, 1-14, 2000.

Upadhyay, H. O. and Mahajan, K. K.: Atmospheric greenhouse effect and ionospheric trends, Geophys. Res. Lett., 25, 3375-3378, 1998. 